\title{
SUBSTANTIATION OF AN APPROACH TO DETERMINATION OF KETOPROFEN MACROGOL 400 ESTERS
}

\author{
Elena Bezuglaya, Igor Zinchenko, Nikolay Lyapunov, Hanna Vlasenko, \\ Vladimir Musatov
}

The aim. The work is concerned with the substantiation of the approach to the identification and quantitative determination of ketoprofen macrogol 400 esters.

Materials and methods. Ketoprofen, macrogol 400, ketoprofen macrogol 400 ester (KM400E), as well as model creamgels were studied by the following methods: absorption spectrophotometry ultraviolet (UV) and visible, highperformance liquid chromatography (HPLC), gas chromatography (GC), GC / mass spectrometry, nuclear magnetic resonance (NMR) spectrometry and thermogravimetry.

Results. It was found by GC and GC / mass spectrometry that the average molecular mass ( $\left.M_{r}\right)$ of the test macrogol 400 is 383.50 and it contains oligomers with molecular masses from 150.17 to 546.65. KM400E, which is a mixture of esters of ketoprofen with macrogol oligomers, was synthesized. The formed esters were characterized by ${ }^{1} \mathrm{H} N M R$ spectra. It was shown that the ratio of the average molecular mass of KM400E, calculated for monoesters, and the molecular mass of ketoprofen corresponds to the ratio of specific absorbances of solutions of ketoprofen and solutions of KM400E, this fact indicated the formation of monoesters. Taking into account the risk of variability of the fractional composition of macrogol 400 in different batches, it is advisable to quantify KM400E using ketoprofen reference standard (RS) and not KM400E RS. Using HPLC with diode array detection the peak of KM400E should be identified by the $U V$ absorption spectrum with $\lambda_{\max } \approx 255 \mathrm{~nm}$, which is characteristic for ketoprofen, and the relative retention time (RRt) of the peak; KM400E should be quantified by the content of ketoprofen in this impurity.

During storage of model cream-gels the content of KM400E impurity is significantly lower than the content of ketoprofen propylene glycol ester (mixture of isomers).

Conclusions. The approach to the identification and quantitative determination of KM400E is substantiated. The analytical procedure for determination of KM400E impurity by HPLC with a diode array detection using ketoprofen RS was developed. Correctness of the procedure was proved by the results of the validation studies.

Keywords: ketoprofen, macrogol 400, ester, impurity, chromatogram, absorption spectrum, molecular mass

How to cite:

Bezuglaya, E., Zinchenko, I., Lyapunov, N., Vlasenko, H., Musatov, V. (2021). Substantiation of an approach to determination of ketoprofen macrogol 400 esters. ScienceRise: Pharmaceutical Science, 3 (31), 51-63. doi: http://doi.org/10.15587/2519-4852.2021.235980

\section{Introduction}

Semi-solid preparations (SSP) for cutaneous application, containing non-steroidal anti-inflammatory drugs (NSAIDs) are effective for treatment of inflammatory diseases of the musculoskeletal system and for relieving pain in joints and muscles [1], in particular, for osteoarthritis (OA) [2]. For the symptomatic treatment of OA, ketoprofen (in the form of gels and creams) is an effective NSAID [3], which has advantages in efficacy and safety compared to ibuprofen and diclofenac [4]. Ketoprofen is promising for the treatment of OA with cutaneous application of SSP in combination with glucosamine hydrochloride [5], and for effective analgesia with levomenthol and methyl salicylate [6]. However, combined SSP with ketoprofen are not available in the pharmaceutical market [7]. Instead of developing combined drugs, studies on the synthesis of prodrugs are conducted, in particular, using ketoprofen and glucosamine as starting materials [8].
Ketoprofen as a drug substance is standardized in the relevant monographs of leading pharmacopoeias $[9,10,11]$ and in the monograph "Ketoprofen" of the State Pharmacopoeia of Ukraine (SPhU) [12]. By definition, ketoprofen is (2RS)-2-(3-benzoylphenyl) propanoic acid, which can form salts with inorganic or organic alkalis and esters with substances containing hydroxyl group(s). Ketoprofen is practically insoluble in water; the formation of salts contributes to the solubility of ketoprofen [6]. The esterification reaction is used for the synthesis of ketoprofen esters, which are investigated as prodrugs [13]. The formation of esters with different substances (menthol, thymol, eugenol, etc.) affects the analgesic efficacy and ulcerogenic potential not only of ketoprofen [13], but also of other derivatives of propionic acid, such as ibuprofen [14, 15]. Experiments on experimental animals have shown that esters of ketoprofen with polyethylene glycols can be considered as promising prodrugs, because when they were administered intramuscularly their analgesic efficacy and anti-inflammatory effect were better 
than effectiveness of ketoprofen [16]. However, ketoprofen esters formed due to its interaction with other substances during storage of SSP (for example, ketoprofen esters with levomenthol [6]) should be considered as impurities that need to be defined and appropriately standardized [17].

In order to therapeutic action, ketoprofen and other NSAIDs must be in a dissolved state in SSP for cutaneous application, which is a condition for their transdermal penetration [18]. SSP should include hydrophilic non-aqueous solvents, which perform the functions of both solvents and penetration enhancers [19]. In the formation of salts, ketoprofen in gels dissolves in the required quantities at $\mathrm{pH}$ solutions above 5.5 [6]. This is unacceptable, for example, for combination of ketoprofen and glucosamine hydrochloride, which can be stabilized only in an acidic medium at $\mathrm{pH}$ near 3.0 [20]. Since ketoprofen salts are not formed at $\mathrm{pH} \approx 3.0$, it should be dissolved in mixed solvents consisting of water and one or more hydrophilic non-aqueous solvents. The composition of the mixed solvent should allow the simultaneous formation of stable solutions of the hydrophobic substance ketoprofen and the hydrophilic substance glucosamine hydrochloride [20].

Ketoprofen forms esters with hydrophilic solvents containing hydroxyl groups in their molecules; the content of esters increases with decreasing $\mathrm{pH}$ of solutions from 7 to 3 [21]. The formation of ketoprofen esters with hydrophilic solvents decreases in a number as follows [21]: ethanol> glycerol> propylene glycol (PG)> diethylene glycol monoethyl ether (DME)> macrogol 400 [21, 22]. Ketoprofen does not form esters with penetration enhancers such as dimethyl sulfoxide (DMSO) and $N$-methylpyrrolidone ( $N$-MP) [21], molecules of which do not contain hydroxyl groups [22]. The solubility of NSAIDs in such binary solvents is improved only at concentrations of $N$-MP or DMSO above 50-60 mass\% [23]. However, at such concentrations, $N$-MP and DMSO can be irritating to the skin [22]. Therefore, it is rational to use $N$-MP or DMSO in lower concentrations in a mixture with water and a third hydrophilic solvent, which can promote the solubility of ketoprofen and glucosamine hydrochloride, but does not irritate the skin. Macrogol 400 is the most suitable for this, because the proportion of hydroxyl groups which participate in reaction with ketoprofen with formation the esters in this solvent is lower compared to ethanol, glycerol, PG and DME.

Esters of ketoprofen with macrogol 400, formed during storage of SSP, are products of interaction of active ingredient and excipient (relative substances), which must be investigated at the stage of pharmaceutical development [24], as well as identified and quantified in routine quality control of the medicinal product [17]. In the monograph "Ketoprofen Gel" of the British Pharmacopoeia, the content limit of ketoprofen ethyl ester (KEE) is $\leq 4.0 \%$; determination is carried out by HPLC [10]. An appropriate reference standard (RS) is required to determine the identified impurity. Among the leading pharmacopoeias only the British Pharmacopoeia offers a single RS of ketoprofen ester Ketoprofen Ethyl Ester BP CRS (Cat. № 667). LGC GmbH [25] supplies $7 \mathrm{RS}$ of ketoprofen esters: Ketoprofen 2,3-Butylene Glycol Ester (Cat. № MM0001.35), Ketoprofen 2-Ethylhexyl Ester (Cat. № MM0001.33), Dexketoprofen Ethyl Ester (Cat. № MM3535.02), Dexketoprofen Isopropyl Ester (Cat. № MM3535.03), Dexketoprofen Me- thyl Ester (Cat. № MM3535.01), Ketoprofen Methyl Ester (Cat. № MM0001.32), Ketoprofen Propylene Glycol Ester (mixture of isomers) (Cat. № MM0001.28). TLC Pharmaceutical Standards Ltd. [26] supplies 2 RS of ketoprofen esters: Ketoprofen 1,4-Sorbitol Ester (Cat. № K-0229), Ketoprofen Propylene Glycol Ester (Cat. № K-0231).

Thus, KM400E RS is not available. KEE is a mixture of ethyl esters of enantiomers of ketoprofen, and ester of ketoprofen with PG is a mixture of esters-isomers formed by the interaction of ketoprofen with different hydroxyl groups of PG. In contrast, KM400E might be a complex mixture of mono- and diesters of ketoprofen and oligomers of macrogol 400 with different relative molecular mass $\left(M_{r}\right)$. The average $M_{r}$ of macrogol 400 in different batches from different manufacturers can vary from 380 to $420(400 \pm 5 \%)$ [22]. The hydroxyl value of macrogol 400 according to the monograph "Macrogols" of the European Pharmacopoeia [9] should be in the range from 264 to 300 . Probable difference between average $M_{r}, M_{r}$ distribution of oligomers and hydroxyl values of macrogol 400 used for RS, and macrogol 400 which is ingredient of the SSP with ketoprofen, might increase the uncertainty of the results of the analysis of KM400E impurity and poses a risk to their accuracy.

In view of the above, it is important to substantiate the approach to the identification and quantitative determination of ketoprofen macrogol 400 esters.

The aim of the research. Substantiation of the approach to identification and quantitative determination of ketoprofen macrogol 400 esters.

\section{Planning (methodology) of the research}

To achieve this goal, the main object of study was to be KM400E, which should have been synthesized according to the method described in the literature [13]. The objects of research were also the starting materials for synthesis: ketoprofen and macrogol 400, which had to meet pharmacopoeial requirements $[9,12]$. In regard to the macrogol 400 selected for synthesis, it was necessary to determine the mass distribution of oligomers by their relative molecular mass $\left(M_{r}\right)$ and to calculate the average $M_{r}$; for this aim GC and GC / mass spectrometry should have been used [27]. Accordingly, it was necessary to validate the analytical procedure for quantifying of macrogol 400 by GC. The synthesized KM400E had to be characterized. The formation of ester should have been proved by the ${ }^{1} \mathrm{H}-\mathrm{NMR}$ spectra. In addition, it was necessary to characterize the KM400E by the UV absorption spectrum and the specific absorption index $\left(A_{1 \mathrm{~cm}}^{1 \%}\right)$ using the absorption spectrophotometry UV and visible. Using HPLC, GC and thermogravimetric analysis, the total content of ketoprofen, the content of unreacted ketoprofen and macrogols, as well as the content of volatile impurities in the synthesized substance should also have been determined.

Thereafter, the method of identification and quantitative determination of KM400E had to be chosen. It had been previously shown that other esters of ketoprofen can be determined by HPLC using not only RS of corresponding esters, but also ketoprofen RS, taking into account the correction factors. This is due to the fact that ketoprofen and its esters in solutions have identical UV absorption spectra with a maximum absorption at $\lambda \max =255 \mathrm{~nm}$, because they contain the same chromophore in the mole- 
cules. As the $M_{r}$ of ester increases, the specific absorbance decrease proportionally, and the correction factors increase [28]. Identification and quantitative determination of KM400E was performed by HPLC with diode array detection. Information on the correction factors calculated from the ratio between the values of specific absorbance of ketoprofen and KM400E solutions, as well as between the average $M_{r}$ of KM400E and $M_{r}$ of ketoprofen, would determine how many hydroxyl groups in the oligomer molecules have participated in reaction of the esterification.

To determine KM400E, an analytical procedure was proposed that was used for determination of other ketoprofen esters by gradient elution HPLC using ketoprofen RS [6]. The validation results should have confirmed the suitability of this procedure for determination of KM400E.

According to the results of experimental studies, the approach to the identification and quantitative determination of KM400E should be substantiated. Thereafter, it was planned to determine the content of ketoprofen in $\mathrm{KM} 400 \mathrm{E}$ and the content of KM400E in cream-gels containing ketoprofen (in dissolved state) and macrogol 400 or $\mathrm{PG}$ at $\mathrm{pH} \approx 3.0$, after long-term storage for 2 years at $25^{\circ} \mathrm{C}$. These data should have proved the rationale for using macrogol 400 in the SSP containing a combination of ketoprofen and glucosamine hydrochloride.

\section{Materials and methods}

The following substances were used in the experiment: ketoprofen (Societa Italiana Medicinali Scandic, Italy), glucosamine hydrochloride (WIRUD GmbH, Germany), macrogol 400 (Panreac, USA), PG (DOW Chemical Company, Germany), $N$-MP (Ashland Specialty Ingredients, USA), purified water (hereinafter water), sodium metabisulfite (Sigma-Aldrich, USA). These substances met the requirements of the monographs of the European Pharmacopoeia [9]. Ketoprofen BP CRS (cat. № 668; $\mathrm{C}_{16} \mathrm{H}_{14} \mathrm{O}_{3}, M_{r}$ 254.28, declared content $99.9 \%$ ) was used in analytical studies.

Weighing of samples was performed using analytical balances AUW 120D ("Shimadzu", Japan). Laboratory balances Gibertini Europe C 500 ("Gibertini", Italy) also was used for weighing. The solutions were prepared by mass-volume technique. The weighted substances were placed in volumetric amber glass flasks (class A, Simax, Czech Republic), dissolved in a part of the solvent and dilute to the necessary volume with the same solvent.

For the synthesis of KM400E, macrogol 400 (3.2 g; $8.00 \mathrm{mmol})$ was added into solution of ketoprofen $(2.0 \mathrm{~g}$; $7.87 \mathrm{mmol})$ in methylene chloride $(25 \mathrm{ml})$, followed by $N, N^{\prime}$-dicyclohexylcarbodiimide $(1.7 \mathrm{~g} ; 8.25 \mathrm{mmol})$ and $N, N^{\prime}$-dimethylaminopyridine $(0.02 \mathrm{~g} ; 0.16 \mathrm{mmol})$. The reaction mixture was kept at room temperature for $12 \mathrm{~h}$, filtered thereafter through a paper filter to separate the precipitated N,N' dicyclohexyl urea. Then the filtrate was dried under reduced pressure. The product was purified by column chromatography on silica gel $60 \mathrm{~m}$ using chloroform - ethyl acetate (10:1) and then chloroform - methanol (20:1) as eluents. The eluent was evaporated using a rotary evaporator under reduced pressure $(650 \mathrm{mBar})$ and at $80{ }^{\circ} \mathrm{C}$ to constant mass. The yield was $77.3 \%$.

The synthesized KM400E was used as a research object.
${ }^{1} \mathrm{H}$ NMR spectra were obtained using Varian MR400 NMR spectrometer (Varian, Inc., USA; software: VnmrJ version 3.2 revision A) at $400 \mathrm{MHz}$ with tetramethylsilane (TMS) as internal standard and deuterated chloroform $\left(\mathrm{CDCl}_{3}\right)$ as a solvent.

The total content of volatile impurities in KM400E was determined by the change in mass of the sample during vacuum drying. The mass of the sample was determined using micro balances Mettler XP26 ("Mettler-Toledo", USA) with an accuracy of $1 \cdot 10^{-5} \mathrm{~g}$. Vacuum drying was performed using a concentrator "Concentrator Plus" ("Eppendorf", Austria) without centrifugation at a pressure of 0.2 mbar, in an air atmosphere at $45^{\circ} \mathrm{C}$ for 5 hours.

Macrogol 400 was analysed by GC and GC / mass spectrometry [9, 12]. Macrogol 400 oligomers were identified by the order of peaks on chromatograms and by molecular masses found by mass spectra.

Mass spectra were obtained on Agilent 7890A GC System chromatograph with an Agilent 5975C massselective detector (Agilent Technologies, USA; software: Agilent Technologies Chem Station Rev. B04.03 [16] 2010).

Chromatography conditions: capillary quartz column HP-5ms size $30 \mathrm{~m} \times 0.25 \mathrm{~mm}$ (stationary phase $-5 \%$ phenyl - $95 \%$ methylpolysiloxane, film is $0.25 \mu \mathrm{m}$ ) (“Agilent Technologies”, cat. № 29091S-433 ) injector port temperature $280^{\circ} \mathrm{C}$; the temperature of the column thermostat is programmed: from $40{ }^{\circ} \mathrm{C}$ is raised at a rate of $20{ }^{\circ} \mathrm{C} / \mathrm{min}$ to $160{ }^{\circ} \mathrm{C}$, maintained for $1 \mathrm{~min}$, then raised at a rate of $5{ }^{\circ} \mathrm{C} / \mathrm{min}$ to $280{ }^{\circ} \mathrm{C}$ and maintained for $25 \mathrm{~min}$; flow rate of carrier gas (helium for chromatography $R$ ): $1 \mathrm{ml} / \mathrm{min}$; the split ratio 50:1; injection volume $1 \mu \mathrm{l}$; ionization energy $70 \mathrm{eV}$; mass scanning range from $45 \mathrm{~m} / \mathrm{z}$ to $950 \mathrm{~m} / \mathrm{z}$.

The mass spectra of the macrogol 400 oligomers were interpreted using the NIST MS Search 2.0f mass spectrum library. The peaks were enumerated from peak of triethylene glycol.

On the mass spectra of macrogol 400 oligomers obtained in the mode of ionization by electron impact $(70 \mathrm{eV})$, there is no molecular ion, because there is a rupture of interatomic bonds in the molecules of macrogol oligomers with the formation of fragment ions, i.e., fragmentation of molecules by $\mathrm{HO}\left(\mathrm{C}_{2} \mathrm{H}_{4}\right)_{n} \mathrm{H} \rightarrow\left(\mathrm{C}_{2} \mathrm{H}_{4} \mathrm{O}\right) \mathrm{H}^{+}+\left(\mathrm{C}_{2} \mathrm{H}_{4} \mathrm{O}\right)_{x} \mathrm{H}^{+}$. Depending on the number of fragments (n) in the molecules of the macrogol oligomers $\mathrm{HO}\left(\mathrm{C}_{2} \mathrm{H}_{4} \mathrm{O}\right)_{n} \mathrm{H}$, the ratio of the peak intensity of the main fragment ion with $\mathrm{M} / \mathrm{Z}=45$ $\left(\left(\mathrm{C}_{2} \mathrm{H}_{4} \mathrm{O}\right) \mathrm{H}^{+}\right)$and the peak intensities of other fragment ions with $M / Z=89,133,177$ and 221 vary. That is, macrogol oligomers can be identified by the presence or absence of peaks of fragment ions with different $\mathrm{M} / \mathrm{Z}$ and by the ratio of the intensities of the peaks of fragment ions [27].

Thereafter, using GC the content of individual oligomers was determined in macrogol 400 by the ratio of peak areas on the chromatograms and average $M_{r}$ was calculated. Chromatograms were obtained on a Shimadzu GC-2030 gas chromatograph with an FID detector and an IOC-20 auto-injector (Shimadzu, Japan) (software: LabSolutions version 5.99).

Chromatography conditions: Capillary quartz column Optima 5 size $30 \mathrm{~m} \times 0.32 \mathrm{~mm}$ (stationary phase $5 \%$ phenyl - $95 \%$ methylpolysiloxane, film $0.25 \mu \mathrm{m}$ ) ("Macherey-Nagel", Germany; cat. № 726314.30), temperature of injector and the detector: $270{ }^{\circ} \mathrm{C}$; the temperature of the column thermostat is programmed: $150{ }^{\circ} \mathrm{C}$ is 
maintained for $1 \mathrm{~min}$, then raised at a rate of $5{ }^{\circ} \mathrm{C} / \mathrm{min}$ to $270{ }^{\circ} \mathrm{C}$ and maintained for $40 \mathrm{~min}$; linear flow rate of the carrier gas (nitrogen for chromatography P): $50 \mathrm{~cm} / \mathrm{s}$; split ratio: 1:30; injection: $1 \mu \mathrm{l}$.

Chromatographic system suitability criteria: the resolution should be at least 3 between the peaks due to any pair of oligomers; the tailing factor of peak of any oligomer should be from 0.8 to 1.5 ; the relative standard deviation (RSD) of the sum of the areas of peaks due to all oligomers should not exceed $3.0 \%$.

Using Shimadzu PharmaSpec UV 1700 spectrophotometer (software: UVProbe version 2.21) the absorption spectra of the solutions were obtained and their absorbance were determined. The specific absorbance values of ketoprofen and $\mathrm{KM} 400 \mathrm{E}$ were determined for their solutions in methanol $R$ at $\lambda_{\max }=255 \mathrm{~nm}$ [12].

HPLC studies were performed using Shimadzu Prominence-i LC-2030C 3D liquid chromatograph with a diode array detector (software: LabSolutions Lite version 5.82). Shimadzu LC 2010C HT liquid chromatograph with spectrophotometric detector (software: LCsolution version 1.25) was also used during the study of intermediate precision.

The content of ketoprofen and the content of KM400E (by ketoprofen) were determined using described below analytical procedure for identification and quantitative determination of ketoprofen and KM400E [6], which was developed and validated by the authors.

Method. Test solution: filtered solution of the object to be tested in methanol R. Reference solution and reference solution for test of chromatographic system sensitivity: filtered solutions of ketoprofen RS in methanol R $30 \mu \mathrm{g} / \mathrm{ml}$ and $1.5 \mu \mathrm{g} / \mathrm{ml}$, respectively.

Chromatography conditions: column Discovery ${ }^{\circledR}$ RP Amide C16, size $250 \times 4.6 \mathrm{~mm}$, with a particle size of 5 $\mu \mathrm{m}$ (Supelco, USA; cat. № 505064, ser. № 157514-04 and ser. № 150084-02); mobile phase A (MP A) - phosphate buffer solution $\mathrm{pH} 5.9$ and acetonitrile for chromatography $R$ (70:30); mobile phase B (MP B) - phosphate buffer solution $p H 5.9$ and acetonitrile for chromatography $R$ (30:70); the mobile phase is programmable: from (0-4) minutes MP $\mathrm{A}$ is $100 \%$, MP B - 0\%, (4-15 min) MP A - $100 \% \rightarrow$ $\rightarrow 0 \%, \mathrm{MP} \mathrm{B}-0 \% \rightarrow 100 \%,(15-20 \mathrm{~min}) \mathrm{MP} \mathrm{A}-0 \%$, MP B $-100 \%,(20-22$ min) MP A $-0 \% \rightarrow 100 \%$, MP B $100 \% \rightarrow 0 \%,(22-26 \mathrm{~min}) \mathrm{MP}$ A $100 \%$, MP B $0 \%$; flow rate $1.5 \mathrm{ml} / \mathrm{min}$; column temperature $40{ }^{\circ} \mathrm{C}$; autoinjector temperature $25{ }^{\circ} \mathrm{C}$; detector - diode array in the range from $200 \mathrm{~nm}$ to $400 \mathrm{~nm}$, detection at $\lambda=255 \mathrm{~nm}$; injection: $10 \mu$; run time 26 minutes. During chromatography, the absorption spectra of substances at peak highs were obtained and the purity of the peaks was determined. The chromatographic system suitability criteria are provided in Table 6.

Validation studies of analytical procedures for quantitative determination were carried out according to the accepted methodology [12, 29]. Acceptance criteria for validation characteristics were calculated in accordance with the requirements of general text 5.3.N.2 of SPhU [12].

The formation of KM400E impurity and ketoprofen PG esters was studied in two model cream-gels, the compositions of which are provided in Table 1.

Table 1

The composition of the studied cream-gels

\begin{tabular}{|l|c|c|}
\hline \multirow{2}{*}{ Component } & \multicolumn{2}{|c|}{$\begin{array}{c}\text { The content of compo- } \\
\text { nents, mass\% }\end{array}$} \\
\cline { 2 - 3 } & $\begin{array}{c}\text { Cream-gel } \\
\text { № 1 }\end{array}$ & $\begin{array}{c}\text { Cream-gel } \\
\text { № 2 }\end{array}$ \\
\hline Ketoprofen & 2.0 & 2.0 \\
\hline Glucosamine hydrochloride & 5.0 & 5.0 \\
\hline Sodium metabisulfite & to $\mathrm{pH} \approx 3.0$ & to $\mathrm{pH} \approx 3.0$ \\
\hline$N$-Methylpyrrolidone & 18.0 & 18.0 \\
\hline Macrogol 400 & 23.7 & - \\
\hline Propylene glycol & - & 32.0 \\
\hline $\begin{array}{l}\text { A mixture of emulsifiers } \\
\text { of the 1st and 2nd kind }\end{array}$ & 6.0 & 6.0 \\
\hline Polymer & 2.0 & 2.0 \\
\hline Oil phase & 6.0 & 6.0 \\
\hline Purified water & to 100.0 & to 100.0 \\
\hline
\end{tabular}

The active substances in the cream-gels were in dissolved state. Cream-gels were stored in aluminium tubes at $(25 \pm 2){ }^{\circ} \mathrm{C}$ for 24 months.

Test solution of cream-gel. Place $0,50 \mathrm{~g}$ of creamgel in a volumetric amber glass flask with a capacity of $25 \mathrm{ml}$, add $10 \mathrm{ml}$ of methanol $R$ and mix to obtain a homogeneous dispersion. Dilute the content of the flask to $25 \mathrm{ml}$ with methanol $R$ and mix. Transfer $5 \mathrm{ml}$ of this dispersion to centrifuge tube and centrifuge for $10 \mathrm{~min}$ at $12000 \mathrm{rpm}$. Filter the transparent liquid through a membrane filter (pore diameter of $0.45 \mu \mathrm{m}$; nylon, Phenomenex, cat. № AF0-1107-12), discharging the first portion $(1.0 \mathrm{ml})$ of the filtrate to waste.

Esters of ketoprofen with PG were identified and quantified by HPLC according to a validated analytical procedure developed by authors and described in the literature [28].

The potentiometric determinations of $\mathrm{pH}$ (2.2.3) [9, 12] were conducted using a $\mathrm{pH}$ meter "Metrohm 827 lab" ("Metrohm", Switzerland) with an electrode "Porotrode" ("Metrohm”, Switzerland; cat. № 6.0235.200 ).

\section{Research results}

Fig. 1 shows the chromatogram of solution of macrogol 400 obtained using gas chromatograph with a FID detector. The procedure is specific because the resolutions between peaks of all oligomers meet requirements and their retention times (Rt) and Rt of the solvent (methanol) are different. 


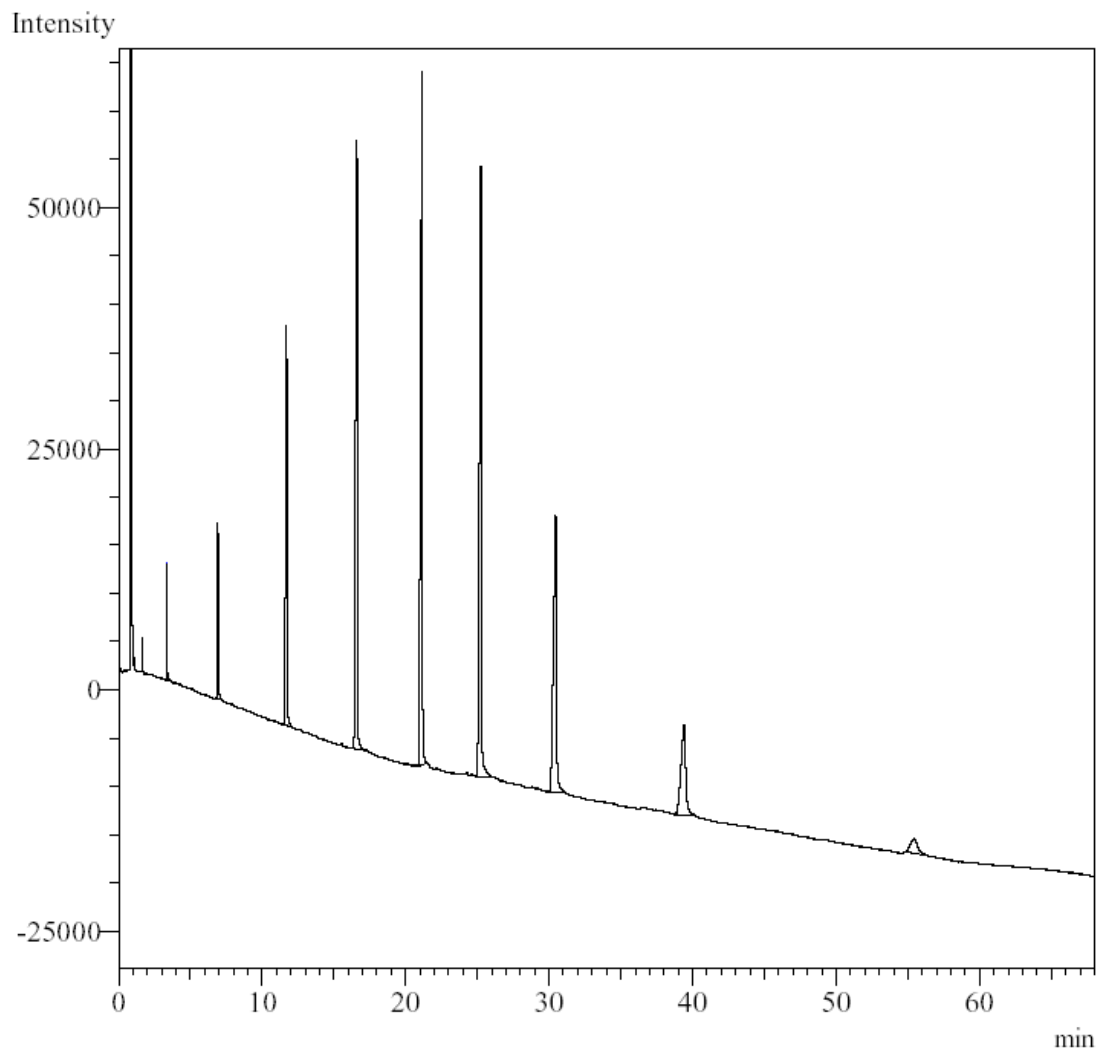

Fig. 1. Chromatogram of a solution of macrogol 400 in methanol $R 25 \mathrm{mg} / \mathrm{ml}$

The results of validation studies of the analytical procedure for quantitative determination of macrogol 400 by GC in regard to linearity, repeatability and accuracy, as well as their evaluation against the acceptance criteria are shown in Table 2 . The analytical procedure for quantitative determination determination of macrogol 400 by the content of individual oligomers meets the acceptance criteria in regard to linearity, repeatability and accuracy at tolerances of $\pm 10 \%$ (Table 2). Acceptance criteria for linearity were calculated according to SPhU 2.0 (5.3.N.2) for the range from $10 \%$ to $120 \%$ of the concentration of macrogol 400 in the reference solution [12].

Table 2

Evaluation of validation characteristics of the analytical procedure for quantitative determination of macrogol 400 against the acceptance criteria [12]

\begin{tabular}{|c|c|c|c|}
\hline Parameter & Value & Criterion $(n=9)$ & Conclusion \\
\hline \multicolumn{4}{|c|}{ Linearity } \\
\hline$b$ & 1.00930 & & \\
\hline$S_{b}$ & 0.01191 & & \\
\hline$\alpha$ & -0.27358 & $\begin{array}{l}\text { 1) } \leq\left|S_{\alpha} \cdot 1.8946\right|=|1.67| \\
\text { 2) if it does not meet criterion (1), then } \\
\leq|1.14|\end{array}$ & $\begin{array}{l}\text { Meets the } \\
\text { criterion }\end{array}$ \\
\hline$S_{\alpha}$ & 0.88134 & & \\
\hline$S D_{0}, \%$ & 1.29253 & & \\
\hline$S D_{0} / b, \%$ & 1.28062 & $\leq|1.69|$ & $\begin{array}{l}\text { Meets the } \\
\text { criterion }\end{array}$ \\
\hline$r$ & 0.99951 & $>|0.99899|$ & $\begin{array}{l}\text { Meets the } \\
\text { criterion }\end{array}$ \\
\hline \multicolumn{4}{|c|}{ Repeatability } \\
\hline relative standard deviation $\mathrm{RSD}_{\mathrm{z}}, \%$ & 1.5210 & & \\
\hline $\begin{array}{l}\text { relative confidence interval } \\
\Delta_{\mathrm{z}}=\mathrm{t} \cdot(95 \%, 9-1) \cdot \mathrm{RSD}_{\mathrm{z}}\end{array}$ & 2.8283 & $<3.2 \%$ & $\begin{array}{l}\text { Meets the } \\
\text { criterion }\end{array}$ \\
\hline \multicolumn{4}{|c|}{ Accuracy } \\
\hline average $\mathrm{Z}, \%$ & 100.34 & & \\
\hline systematic error $\delta, \%$ & 0.34 & $\begin{array}{c}\text { 1) } \leq \Delta_{\mathrm{z}}: \sqrt{ } 9=0.94 \% \\
\text { 2) if it does not meet criterion (1), } \\
\text { then } \\
\leq 0.32 \cdot 3.2 \%=1.02 \%\end{array}$ & $\begin{array}{l}\text { Meets the } \\
\text { criterion }\end{array}$ \\
\hline
\end{tabular}


The quantitation limit (QL) and detection limit (DL) of macrogol 400, calculated by the signal-to-noise ratio $(\mathrm{S} / \mathrm{N})$ for the peak with smallest area due to oligomer with $M_{r} 546.65$, are $35.60 \mu \mathrm{g} / \mathrm{ml}$ and $10,68 \mu \mathrm{g} / \mathrm{ml}$ respectively. The range of the analytical procedure is from $4.5 \mathrm{mg} / \mathrm{ml}$ to $60.5 \mathrm{mg} / \mathrm{ml}$. At lower concentrations of macrogol 400, the ratio of $\mathrm{S} / \mathrm{N}$ for peak of the oligomer with $M_{r} 546.65$ does not meet the criterion $\mathrm{S} / \mathrm{N} \geq 10$, and at higher concentrations, the tailing factors for the peaks of the individual oligomers are more than 1.5.

In the synthesized KM400E the content of impurities of individual oligomers of macrogol 400, determined by GC according to the validated procedure, was $5.8 \%$.

There are peaks of 10 oligomers on the chromatogram of the solution of macrogol 400 (Fig. 1). By selective gas chromatography / mass spectrometry with elec- tron ionisation the mass spectra were obtained and the $M_{r}$ of individual oligomers were calculated using them. A representative mass spectrum of triethylene glycol, which is oligomer with $M_{r} 150.17$, is shown on Fig. 2.

The sequential order of peaks of oligomers in accordance with increasing of their $M_{r}$ provides the opportunity to determine their content in the macrogol 400 (Table 3).

Macrogol 400 contains condensation products of ethylene oxide with $M_{r}$ from 150.17 to 546.65 (n from 3 to 12). The content of oligomers in the macrogol 400 passes through the maximum depending on their $M_{r}$ and is the largest for oligomers with $M_{r} 370.44(\mathrm{n}=8)$. The average $M_{r}$ of the macrogol 400 used in the experiment was 383.5 (Table 3 ).

Fig. 3 shows the ${ }^{1} \mathrm{H}$ NMR spectrum of the synthesized KM400E.

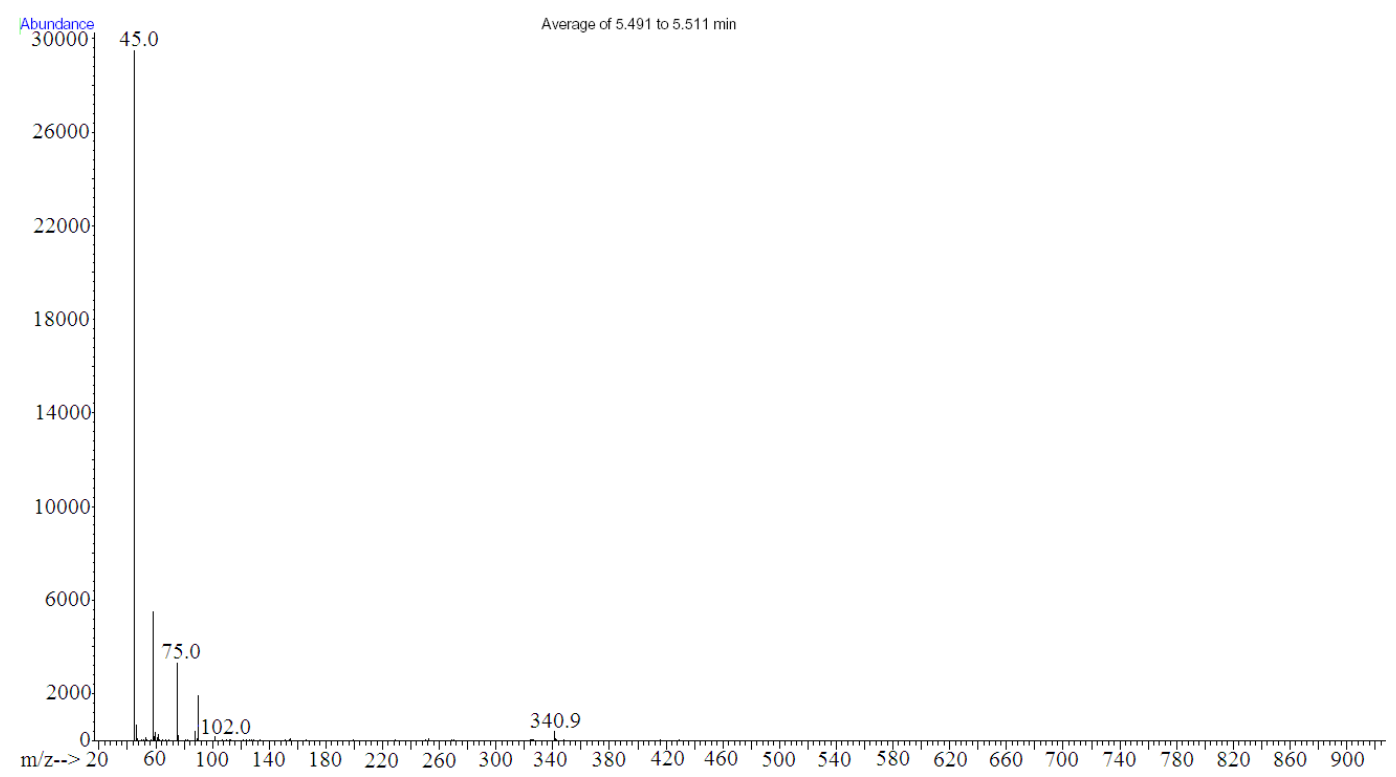

Fig. 2. Representative mass spectrum of triethylene glycol

The results of determining the content of individual oligomers and the average $M_{r}$ of macrogol 400

\begin{tabular}{|c|c|c|c|c|c|c|}
\hline $\mathrm{n}$ & $M_{r}$ & $\begin{array}{c}\mathrm{Rt}, \\
\text { min }\end{array}$ & Peak area & $\%$ of the sum of peak areas & \% of the average $M_{r}$ & Average $M_{r}$ \\
\hline 3 & 150.17 & 1.645 & 6116 & 0.22 & 0.33 \\
\hline 4 & 194.23 & 3.353 & 36487 & 1.33 & 2.59 \\
\hline 5 & 238.28 & 6.908 & 82791 & 3.03 & 7.22 \\
\hline 6 & 282.33 & 11.700 & 259662 & 9.50 & 57.93 \\
\hline 7 & 326.38 & 16.603 & 485319 & 17.75 & 82.11 \\
\hline 8 & 370.44 & 21.133 & 606049 & 22.17 & 89.10 \\
\hline 9 & 414.49 & 25.243 & 587776 & 21.50 & 68.39 \\
\hline 10 & 458.54 & 30.451 & 407831 & 14.92 & 38.99 \\
\hline 11 & 502.59 & 39.408 & 212099 & 7.76 & 10.02 \\
\hline 12 & 546.65 & 55.432 & 50120 & 1.83 & \\
\hline
\end{tabular}

Note: $n$ in the formula of macrogols $\mathrm{H}-\left[\mathrm{OCH}_{2}-\mathrm{CH}_{2}\right]_{n}-\mathrm{OH}$ 


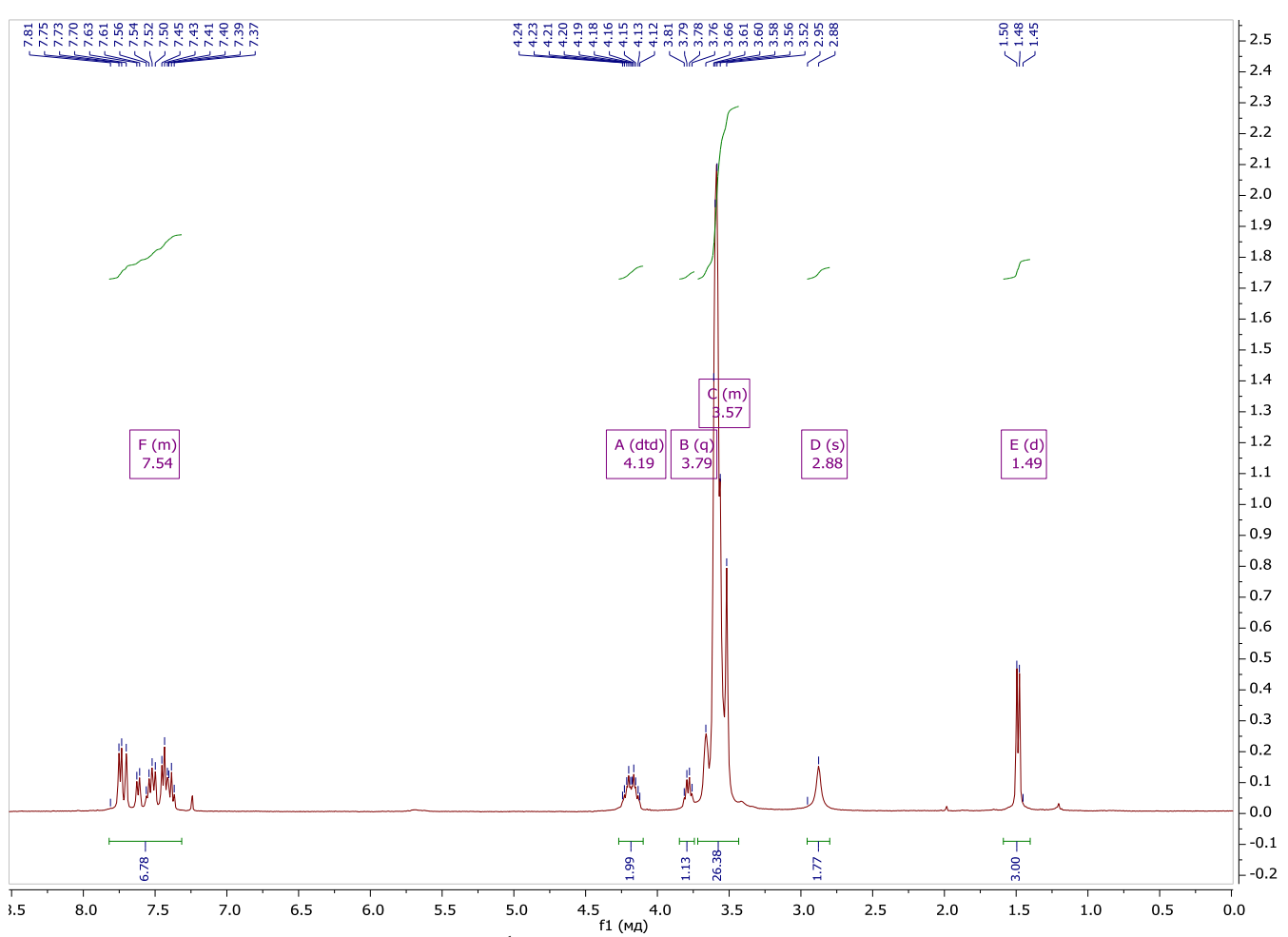

Fig. 3. ${ }^{1} \mathrm{H}$ NMR spectrum of KM400E

On the proton spectrum of the synthesized substance KM400E in addition to the characteristic signals of protons of ketoprofen and macrogol 400 there is a multiplet with integrated intensity in 2 protons with a chemical shift in the range of 4.28-4.08 md, which corresponds to protons near the ester group: ${ }^{1} \mathrm{H}$ NMR $(400 \mathrm{MHz}$, Chloroform- $d$ ) $\delta$ : 7.86$7.31(\mathrm{~m}, 9 \mathrm{H}, \mathrm{Ph}+\mathrm{Ar}), 4.28-4.08\left(\mathrm{~m}, 2 \mathrm{H}, \mathrm{COOCH}_{2}\right)$, 3.79 (q, $J=7.3 \mathrm{~Hz}, 1 \mathrm{H}_{\text {benzyl }}$ ), 3.70-3.32 (m, 28H, PEG), 2.88 (s, $\left.2 \mathrm{H}, \mathrm{CH}_{2} \mathrm{OH}\right) 1.49\left(\mathrm{~d}, \mathrm{~J}=7.0 \mathrm{~Hz}, 3 \mathrm{H}, \mathrm{CH}_{3}\right)$. The presence of the signal of these protons indicates that there was an esterification reaction with the formation of esters of ketoprofen with oligomers of macrogol 400.

The content of volatile impurities in the synthesized KM400E was $3.5 \%$.

The analytical procedure for determination of ketoprofen esters by gradient HPLC [6] is suitable for determination of KM400E, that was demonstrated by the results of validation studies. Fig. 4 shows the chromatograms, which demonstrate the specificity of the test for determination of KM400E.

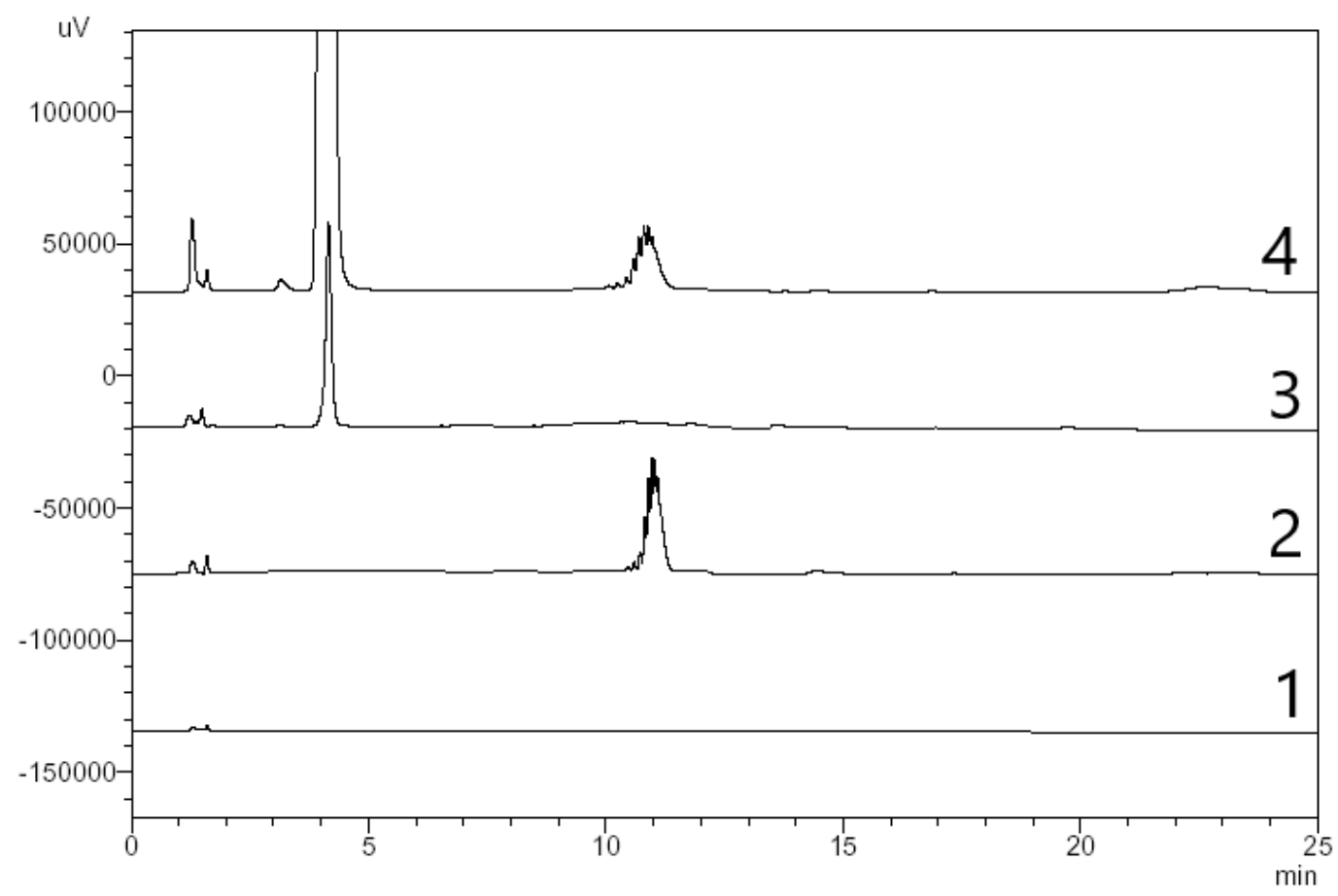

Fig. 4. Chromatograms of solutions of placebo (1), KM400E (2), ketoprofen RS (3) and test solution of creamgel № 1 (4), obtained by the method of determination of KM400E by HPLC, where the peaks with Rt $\sim 4.0$ min correspond to ketoprofen, and peaks with $\mathrm{RT} \approx 11.1 \mathrm{~min}-\mathrm{KM} 400 \mathrm{E}(\mathrm{RRt} \approx 2.8)$ 
KM400E, which is a mixture of ketoprofen esters with oligomers with different $M_{r}$, on chromatogram is as single peak which resolution with peak of ketoprofen is proper. The specificity of the procedure is confirmed by the fact that on the chromatogram of the solution of placebo there are no peaks with retention time which is identical or close to the retention times of peaks of ketoprofen and KM400E (Fig. 4).
The peaks of ketoprofen and KM400E are spectrally pure, because their "Peak purity index" is 1.000000 .

According to the results of validation studies, the analytical procedure for quantitative determination of the KM400E impurity (by ketoprofen) by HPLC meets the acceptance criteria in regard to linearity, repeatability, accuracy and intermediate precision (Table 4).

Table 4

Evaluation of validation characteristics of the analytical procedure for quantitative determination of impurity KM400E

(by ketoprofen) against the acceptance criteria [12]

\begin{tabular}{|c|c|c|c|}
\hline Parameter & Value & Criteria $(n=18)$ & Conclusion \\
\hline \multicolumn{4}{|c|}{ Linearity } \\
\hline$b$ & 0.99912 & & \\
\hline$S_{b}$ & 0.00463 & & \\
\hline$\alpha$ & 0.19361 & $\begin{array}{l}\text { 1) } \leq\left|S_{\alpha} \cdot 1,7459\right|=|0,61| \\
\text { 2) if it does not meet criterion (1), } \\
\text { then } \leq 1,68\end{array}$ & $\begin{array}{l}\text { Meets the } \\
\text { criterion }\end{array}$ \\
\hline$S_{\alpha}$ & 0.34629 & & \\
\hline$S D_{0}, \%$ & 0.76956 & & \\
\hline$S D_{0} / b, \%$ & 0.77024 & $\leq|2,86|$ & $\begin{array}{l}\text { Meets the } \\
\text { criterion }\end{array}$ \\
\hline$r$ & 0.99983 & $>|0,99898|$ & $\begin{array}{l}\text { Meets the } \\
\text { criterion }\end{array}$ \\
\hline \multicolumn{4}{|c|}{ Repeatability } \\
\hline relative standard deviation $\mathrm{RSD}_{\mathrm{z}}, \%$ & 1.3573 & & \\
\hline $\begin{array}{c}\text { relative confidence interval } \\
\Delta_{\mathrm{z}}=\mathrm{t} \cdot(95 \%, 18-1) \cdot \mathrm{RSD}_{\mathrm{z}}\end{array}$ & 2.3611 & $<5,0 \%$ & $\begin{array}{l}\text { Meets the } \\
\text { criterion }\end{array}$ \\
\hline \multicolumn{4}{|c|}{ Accuracy } \\
\hline average $\mathrm{Z}, \%$ & 100.51 & & \\
\hline systematic error $\delta, \%$ & 0.51 & $\begin{array}{l}\text { 1) } \leq \Delta_{\mathrm{z}}: \sqrt{ } 18=0,56 \% \\
\text { 2) if it does not meet criterion (1), } \\
\text { then } \leq 0.32 \cdot 5.0 \%=1,6 \%\end{array}$ & $\begin{array}{l}\text { Meets the } \\
\text { criterion }\end{array}$ \\
\hline \multicolumn{4}{|c|}{ Intermediate precision } \\
\hline combined average $\mathrm{Z}_{\text {intra }}, \%$ & 100.45 & & \\
\hline $\mathrm{SD}_{\text {z-intra }}, \%$ & 1.3814 & & \\
\hline$\Delta_{\text {intra }}=\mathrm{t} \cdot(95 \%, 36-1) \cdot \mathrm{SD}_{\mathrm{z}}$ & 2.3340 & $<5.0 \%$ & $\begin{array}{l}\text { Meets the } \\
\text { criterion }\end{array}$ \\
\hline
\end{tabular}

The values of QL and DL calculated by two methods also meet the acceptance criteria (Table 5). It should be noted that the values of QL and DL defined by the results of study of linearity are greater than the values of QL and DL calculated by the signal-to-noise ratio (S/N) (Table 5). This should be taken into account in case of standardization the content of KM400E impurity in medicinal products.
During the analysis, the chromatographic system suitability criteria are met, and they are not affected by insignificant changes in temperature and flow rate of the mobile phase, that demonstrates the robustness of the procedure (Table 6).

According to Table 7, the test solutions meet the criteria of acceptability for their stability.

Table 5

Quantitation limits (QL) and detection limits (DL) of ketoprofen defined by two methods

\begin{tabular}{|c|c|c|c|c|}
\hline Method & Parameter & Value & Criterion & Conclusion \\
\hline \multicolumn{5}{|c|}{$\mathrm{QL}^{\prime}$} \\
\hline by linearity ${ }^{2}$ & $\mathrm{QL}=10 \cdot S_{\alpha}: b$ & $3.4660 \%$ & \multirow{2}{*}{$<\max \mathrm{QL}=32 \%$} & \multirow{2}{*}{$\begin{array}{l}\text { Meets the } \\
\text { criterion }\end{array}$} \\
\hline by ratio $\mathrm{S} / \mathrm{N}^{3}$ & $\mathrm{QL} \rightarrow \mathrm{S} / \mathrm{N}=10$ & $0.1646 \%$ & & \\
\hline \multicolumn{5}{|c|}{$\mathrm{DL}^{l}$} \\
\hline by linearity $^{2}$ & $\mathrm{DL}=3.3 \cdot S_{\alpha}: b$ & $1.1438 \%$ & \multirow{2}{*}{$<\max \mathrm{DL}=10 \%$} & \multirow{2}{*}{$\begin{array}{l}\text { Meets the } \\
\text { criterion }\end{array}$} \\
\hline by ratio $\mathrm{S} / \mathrm{N}^{3}$ & $\mathrm{DL} \rightarrow \mathrm{S} / \mathrm{N}=3$ & $0.0494 \%$ & & \\
\hline
\end{tabular}

Note: ${ }^{1} Q L$ and DL are given as a percentage of upper limit $4.0 \%$ for acceptable content of impurity KM400E (by ketoprofen); ${ }^{2} Q L$ corresponds to the concentration of ketoprofen in the test solution of $1.040 \mu \mathrm{g} / \mathrm{ml}$, and $\mathrm{DL}-0.3431 \mu \mathrm{g} / \mathrm{ml}$;

${ }^{3} Q L$ corresponds to the concentration of ketoprofen in the test solution of $0.049 \mu \mathrm{g} / \mathrm{ml}$, and DL $-0.015 \mu \mathrm{g} / \mathrm{ml}$ 
Table 6

The results of the study of the robustness of the analytical procedure for determination of ketoprofen

\begin{tabular}{|c|c|c|c|c|}
\hline \multirow[b]{2}{*}{ Conditions } & Column efficiency ${ }^{1}$ & Tailing factor $^{1}$ & $\mathrm{RSD}^{1}, \%$ & $\mathrm{~S} / \mathrm{N}^{2}$ \\
\hline & $\geq 3000$ t. p. & from 0.8 to 1.5 & $\begin{array}{c}\leq 2.11 \% \\
(3 \text { injections })\end{array}$ & $\geq 10$ \\
\hline $\begin{array}{l}\text { Conditions according to the procedure: } \\
\text { temperature } 40{ }^{\circ} \mathrm{C} \text {, flow rate } 1.5 \mathrm{ml} / \mathrm{min} \text {, } \\
\text { column №157514-04 }\end{array}$ & 4746 & 0.978 & 0.147 & 303.78 \\
\hline temperature $35^{\circ} \mathrm{C}$ & 4136 & 0.980 & 0.974 & 447.57 \\
\hline temperature $45^{\circ} \mathrm{C}$ & 3674 & 0.964 & 0.914 & 447.57 \\
\hline flow rate $1.4 \mathrm{ml} / \mathrm{min}$ & 4868 & 0.964 & 0.192 & 624.23 \\
\hline flow rate $1.6 \mathrm{ml} / \mathrm{min}$ & 3719 & 0.957 & 1.506 & 341.45 \\
\hline column №150084-02 & 7400 & 1.051 & 0.809 & 289.58 \\
\hline
\end{tabular}

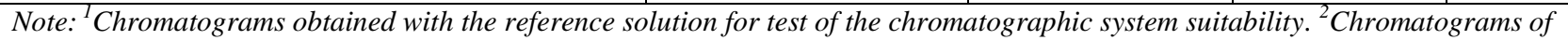
the solution to check the sensitivity of the chromatographic system

Table 7

The results of the study of the stability of model solutions of ketoprofen

\begin{tabular}{|c|c|c|c|c|c|}
\hline $\begin{array}{c}\text { Model solutions } \\
\text { in the study of: }\end{array}$ & $\mathrm{Z}_{\text {first }} \%$ & $\mathrm{Z}_{\text {last }} \%$ & $\begin{array}{c}\left|\Delta \mathrm{Z}_{\mathrm{i}}\right|, \\
\%\end{array}$ & $\begin{array}{c}\text { Criterion: } \\
\left|\Delta \mathrm{Z}_{\mathrm{i}}\right| \leq \sqrt{ } 2 \times 5.0 \% *\end{array}$ & Conclusion \\
\hline repeatability, accuracy, linearity & 103.52 & 99.36 & 4.16 & $4.16 \% \leq 7.07 \%$ & $\begin{array}{c}\text { Meets the } \\
\text { criterion }\end{array}$ \\
\hline intermediate precision & 98.58 & 99.96 & 1.38 & $1.38 \% \leq 7.07 \%$ & $\begin{array}{c}\text { Meets the } \\
\text { criterion }\end{array}$ \\
\hline$* \max \Delta_{A s}=5.0 \%$ &
\end{tabular}

According to the results of validation studies, the analytical procedure for determination of the KM400E impurity (by ketoprofen) is correct. Using this procedure it was found that in the synthesized substance KM400E the content of ketoprofen in ester molecules is $39.4 \%$, and the content of ketoprofen impurity is about $0.029 \%$.

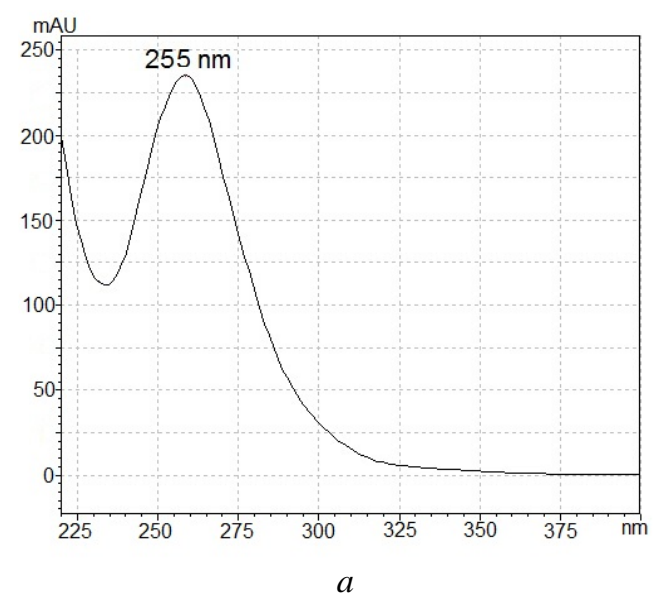

Fig. 5 . UV absorption spectra $\left(\lambda_{\max }=255 \mathrm{~nm}\right)$ obtained at the highs of peaks due to: $a-$ ketoprofen; $b-\mathrm{KM} 400 \mathrm{E}$

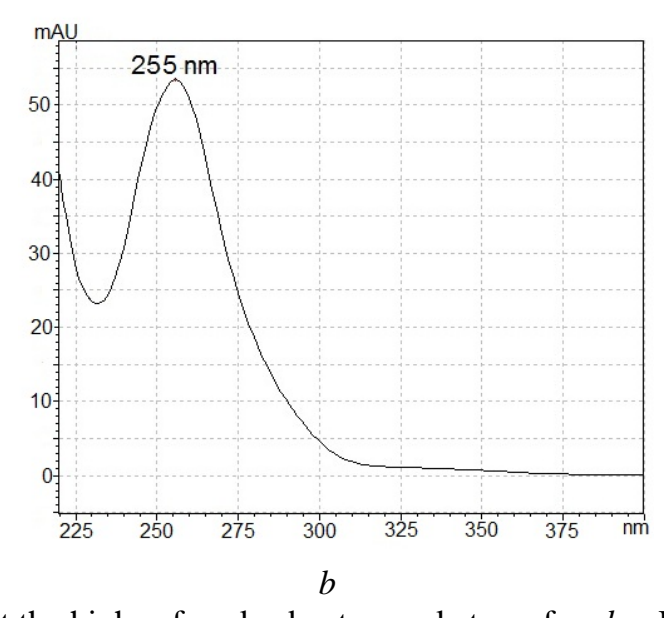
in the range of 230-350 $\mathrm{nm}$ (with absorption maximum at $255 \mathrm{~nm}$ ) is identical to the UV spectrum of ketoprofen solution (Fig. 5), due to the same chromophore [28]. But, the value of specific absorbance of ketoprofen solution is higher, because macrogol 400 does not absorb in the UV range (Table 8$)$.

Table 8

Correction factors for quantitative determination of KM400E using ketoprofen RS, obtained by different methods

\begin{tabular}{|l|c|c|c|c|c|}
\hline \multicolumn{1}{|c|}{ Substance } & $M_{r}$ & $\begin{array}{c}M_{r} \mathrm{KM} 400 \mathrm{E}: \\
M_{r} \mathrm{KN}\end{array}$ & $A_{1 \mathrm{~cm}}^{1 \%}$ & $\begin{array}{c}A_{1 \mathrm{~cm}}^{1 \%} \mathrm{KN}: \\
A_{1 c m}^{1 \%} \mathrm{KM} 400 \mathrm{E}\end{array}$ & $\begin{array}{c}100 \% \mathrm{KM} 400 \mathrm{E}: \\
39,4 \% \mathrm{KN}^{3}\end{array}$ \\
\hline Ketoprofen (KN) & 254.3 & & 661.11 & & \\
\hline Macrogol 400 & 383.5 & & & & 2.3 \\
\hline KM400E & $619.78^{1}$ & 2.4 & $287.53^{2}$ & 2.5 \\
\hline
\end{tabular}

Note: ${ }^{1}$ Average $M_{r}$ by calculation. ${ }^{2}$ Determined taking into account the content of volatile impurities and the content of free oligomers of macrogol $400 .{ }^{3}$ The content of ketoprofen in ester molecules 
The correction factors obtained by different methods are in the range from 2.3 to 2.5 (Table 8 ). The ratio of the average $M_{r}$ of KM400E, calculated for monoesters, and the $M_{r}$ of ketoprofen is 2.4 , the ratio of their specific absorbance -2.3 , the ratio of the mass of KM400E and mass of ketoprofen in esters -2.5 . The average correction factor is 2.4. The obtained data demonstrate that the synthesized KM400E is mainly ketoprofen monoesters with macrogol 400 oligomers.

The chromatograms of the tested solutions of cream-gels № 1 and № 2 after storage at $25^{\circ} \mathrm{C}$ are shown in Fig. 6, 7. Data regarding the content of ketoprofen and ketoprofen esters formed during storage are given in Table 9.

Table 9

The results of the analysis of cream-gels after storage at $25^{\circ} \mathrm{C}$

\begin{tabular}{|c|c|c|c|c|c|}
\hline \multirow{2}{*}{ Cream-gel } & \multirow{2}{*}{ Shelf life, month } & \multicolumn{2}{|c|}{ The content (C) of ketoprofen ${ }^{1}, \mathrm{mg} / \mathrm{g}$} & \multirow{2}{*}{$\begin{array}{c}\text { The content of } \\
\text { esters }\end{array}$} \\
\cline { 3 - 6 } & Initially & After storage & $\begin{array}{c}\text { The difference in } \\
\text { content, } \%\end{array}$ & 2.31 & $2.44^{3}$ \\
\hline № 1 & 18 & 19.5 & 19.05 & 18.83 & $3.28^{3}$ \\
\hline № 1 & 24 & 19.5 & 15.21 & 19.95 & $19.79^{4}$ \\
\hline № 2 & 18 & 19.0 & 13.90 & 26.84 & $26.57^{4}$ \\
\hline № 2 & 24 & 19.0 & & \\
\hline
\end{tabular}

Note: ${ }^{1}$ The content of ketoprofen should be from 18.5 to $21.0 \mathrm{mg} / \mathrm{g} ;{ }^{2}$ The content of esters is calculated by their content of ketoprofen; ${ }^{3}$ KM400E; ${ }^{4}$ Esters of ketoprofen with $P G$

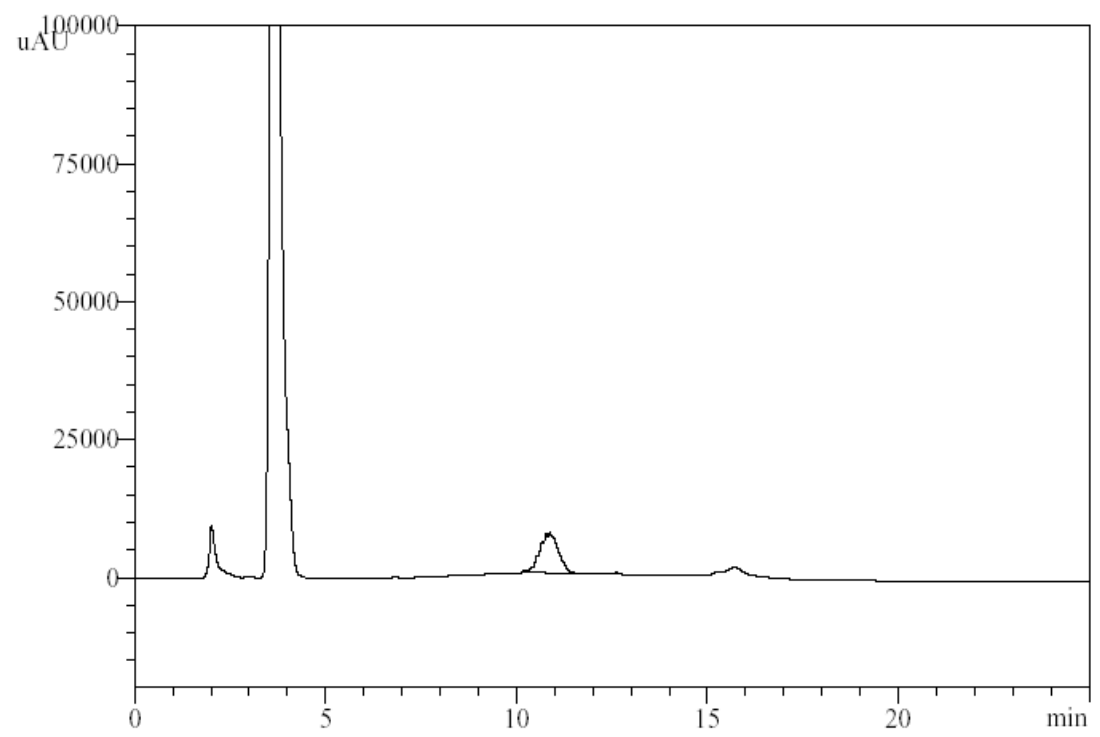

Fig. 6. Chromatogram of the test solution of cream-gel № 1 containing macrogol 400, after 18 months of storage at a temperature of $25^{\circ} \mathrm{C}$, where: the peak with $\mathrm{Rt}=3,642$ min due to ketoprofen (peak purity 1,000000); peak with $\mathrm{Rt}=10,874 \mathrm{~min}(\mathrm{RRt} \approx 3.0$ relative to $\mathrm{Rt}$ peak of ketoprofen) due to $\mathrm{KM} 400 \mathrm{E}$ (peak purity 1,000000 )

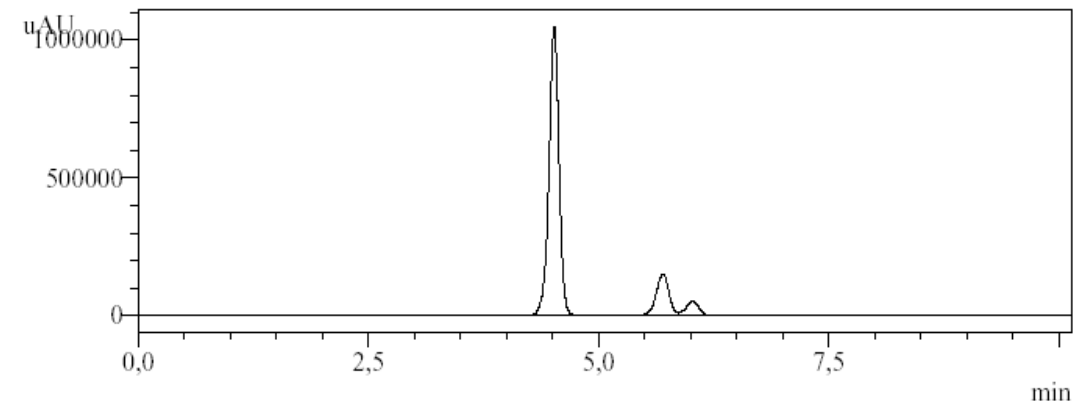

Fig. 7. Chromatogram of the test solution of cream-gel № 2 containing PG, after 18 months of storage at $25^{\circ} \mathrm{C}$, where the peak with $\mathrm{Rt}=4.518 \mathrm{~min}$ due to ketoprofen, and the peaks with $\mathrm{Rt}=5.698 \mathrm{~min}$ and $\mathrm{Rt}=6.022 \mathrm{~min}-$ due to two isomers of ketoprofen PG ester

On the chromatograms of the tested solutions of cream-gel № 1 there is one peak with $\mathrm{Rt} \approx 10.9 \mathrm{~min}$ ( $R R t \approx 3.0$ with reference to ketoprofen) due to 10 esters of ketoprofen with oligomers of macrogol 400 (Fig. 6), but there are two peaks due to ketoprofen PG esters, formed by different hydroxyl groups of PG [21, 28] (Fig. 7).

The content of ketoprofen esters with macrogol 400 or $\mathrm{PG}$ is the greater, the longer the shelf life of the 
cream-gel. However, the content of KM400E impurity, formed during storage of the cream-gel № 1, was 8.1 times lower than the content of ketoprofen PG esters in the cream-gel № 2. Esters are the main impurities of ketoprofen formed in cream-gels, because there is actually a balance between the content of ketoprofen in esters and a decrease in the content of ketoprofen in cream-gels (Tab. 9). When PG is used in the composition of the cream-gel the content of ketoprofen becomes significantly less than the lower limit provided in the monograph "Ketoprofen Gel" of the British Pharmacopoeia (from 92.5 to $105.0 \%$ of the nominal content) [10]; cream-gel № 2 does not meet requirements because of low content of ketoprofen and too high content of ketoprofen PG esters. At the same time, the decrease in the content of ketoprofen in the cream-gel № 1 for 2 years was only $3.44 \%$, and the content of KM400E impurity increased to $3.28 \%$, which is less than the limit of $4.0 \%$ set for KEE impurity [10]. It may be assumed that the cream-gel № 1 with macrogol 400 can meet requirements in regard to content of ketoprofen and KM400E impurity for shelf life of 2 years at a storage temperature not exceeding $25^{\circ} \mathrm{C}$.

\section{Discussion of research results}

Macrogol 400 is a mixture of 10 oligomers with $M_{r}$ from 150.17 to 546.65 ; the content of oligomers passes through the maximum at $M_{r}=370.44(\mathrm{n}=8)$ (Table 3). The results of this study are representative, but different batches of macrogol 400 produced by different companies may differ slightly in relation to the average $M_{r}$ [22], the distribution of oligomers by $M_{r}$ and the number of hydroxyl groups [9] by which the esterification reaction with ketoprofen takes place. The synthesized KM400E contains mainly ketoprofen monoesters with different oligomers, but under certain conditions the formation of diesters is not excluded. Therefore, the use of KM400E RS to quantitative determination of KM400E impurity in the preparations may affect the uncertainty of the analysis results and the balance of masses of the active substance and products its degradation. Currently, reference standard for KM400E are not available on the market $[9,10,11,25,26]$.

The content of other esters of ketoprofen can be determined by HPLC using ketoprofen RS and taking into account the correction factor [28]. But this approach is applicable to individual substances or mixtures of isomers which have the same $M_{r}$. The risk of variability of $M_{r}$ of macrogol 400 makes this approach questionable for the quantitative determination of KM400E impurity. Moreover, the correction factors in the case of one substance KM400E, calculated by different methods (by the ratio of $M_{r}$, specific absorbace and content of ketoprofen in the esters) are slightly different from each other (Table 8). Calculating the content of KM400E using the correction factor can increase the uncertainty of the analysis results.

It is rational to quantify and standardize the content of the KM400E impurity by HPLC by the content of ketoprofen in this substance using ketoprofen RS. This is possible because these substances have the same UV absorption spectra. The identification of KM400E can be performed by the relative retention time of its peak (RRt $\approx 2.8-3.0$ with reference to ketoprofen), by UV absorption spectrum $\left(\lambda_{\max } \approx 255 \mathrm{~nm}\right)$ at the high of peak and by peak purity. If necessary, it is also possible to estimate the content of KM400E impurity as a total, since KM400E is mainly a mixture of monoesters. For this purpose, a correction factor of 2.5 should be used, which is the ratio of the $M_{r}$ of $\mathrm{KM} 400 \mathrm{E}$ and ketoprofen at conditional value 400 for average $M_{r}$ of macrogol 400 .

The analytical procedure for the identification and quantitative determination of KM400E (by ketoprofen) by elution HPLC with a diode array detection using ketoprofen RS was developed and validated. This procedure provide the opportunity to identify and quantify the KM400E impurity formed in the cream-gel, which contains ketoprofen and macrogol 400 (Table 1). The use of the Discovery® RP Amide C16 chromatographic column, $250 \times 4.6 \mathrm{~mm}$, particle size $5 \mu \mathrm{m}$ (Supelco, USA; cat. № 505064) is stipulated by the developed analytical procedure. However, KM400E impurity can be determined under these chromatographic conditions using other chromatographic columns, for example, Supelcosil ABZ+Plus, $150 \times 4.6 \mathrm{~mm}$, particle size $3 \mu \mathrm{m}$ (Supelco, cat. № 59194). Depending on the column parameters the retention time of KM400E can vary from about $9.7 \mathrm{~min}$ to $11.5 \mathrm{~min}$, and the peak line can be smooth or serrated depending on the chromatographic system efficiency and the scale of chromatogram visualization (Fig. 4, 6).

According to the research, it is rational to use macrogol 400 as a solvent in a cream-gel with ketoprofen with acidic medium $(\mathrm{pH} \approx 3.0)$. Based on assessment of decrease in content of ketoprofen and increase in content of KM400E impurity for this product it is possible to establish the shelf life 2 years at a storage temperature not exceeding $25^{\circ} \mathrm{C}$. If PG is used instead of macrogol 400, the medicinal product does not meet the requirements during shelf life because of the low content of ketoprofen and too high content of ketoprofen PG esters impurity (Table 9). This can be explained mainly by the fact that PG and macrogol 400 in their molecules have different proportions of hydroxyl groups, which participate in the esterification reaction. In the molecules of macrogol 400, the reaction occurs mainly with one hydroxyl group, the contribution of which to the $M_{r}$ of macrogol 400 is $4.43 \%$. In PG molecules both hydroxyl groups react, whose contribution to the $M_{r}$ of PG is $44.7 \%$. That is, the proportion of reacting hydroxyl groups in PG molecules is 10 times higher, and the content of formed ketoprofen PG esters is 8.1 times higher (Table 9).

This article does not provide results of studies in regard to the formation of esters of other NSAIDs (e.g., ibuprofen) with a macrogol of 400 . However, the results of the studies presented in this article could provide a basis for their identification, quantitative determination and standardization. Probably, it is promising to formulate SSP using macrogols with a higher $M_{r}$ and a lower hydroxyl number, suggesting the lower content of esters of NSAIDs with macrogols.

The obtained results can be used in the development and standardization of a combined preparation in the form of a cream-gel containing ketoprofen and glucosamine hydrochloride and intended for topical treatment of OA.

\section{Conclusions}

According to the results of experimental studies, the approach to the identification, quantitative 
determination and standardization of ketoprofen macrogol 400 esters, which are formed as impurities in SSP with an acidic medium, is substantiated. It is shown that the identification of KM400E should be performed by the its relative retention time (reference to ketoprofen), UV absorption spectrum at the high of peak and peak purity. It is proposed to quantify and standardize the content of KM400E impurity by HPLC by the content of ketoprofen in this substance. A new analytical procedure for the determination of ketoprofen macrogol 400 esters by gradient elution HPLC with a diode array detection using ketoprofen RS was developed. The correctness of the method was proved by the results of validation studies.

It was found that macrogol 400 (in contrast to PG) is rational to use as one of the solvents for ketoprofen in SSP with acidic medium, because the formation of ketoprofen macrogol 400 esters and decrease in content of ketoprofen is minor, that ensures compliance with specifications for 2 years.

\section{Conflict of interests}

The authors declare that they have no conflicts of interest.

\section{Financing}

The study was performed without financial support.

\section{Acknowledgment}

The authors are grateful to Doctor of Physics and Mathematics O. V. Vashchenko for the assistance in thermogravimetric analysis and to Candidate of Chemical Sciences O. M. Semenenko for assistance in synthesis.

\section{References}

1. Derry, S., Wiffen, P. J., Kalso, E. A., Bell, R. F., Aldington, D., Phillips, T. et. al. (2017). Topical analgesics for acute and chronic pain in adults - an overview of Cochrane Reviews. Cochrane Database of Systematic Reviews, 5. doi: http://doi.org/10.1002/ 14651858.cd008609.pub2

2. Zeng, C., Wei, J., Persson, M. S. M., Sarmanova, A., Doherty, M., Xie, D. et. al. (2018). Relative efficacy and safety of topical non-steroidal anti-inflammatory drugs for osteoarthritis: a systematic review and network meta-analysis of randomised controlled trials and observational studies. British Journal of Sports Medicine, 52 (10), 642-650. doi: http://doi.org/10.1136/bjsports-2017-098043

3. Rother, M., Conaghan, P. G. (2013). A Randomized, Double-blind, Phase III Trial in Moderate Osteoarthritis Knee Pain Comparing Topical Ketoprofen Gel with Ketoprofen-free Gel. The Journal of Rheumatology, 40 (10), 1742-1748. doi: http://doi.org/10.3899/ jrheum.130192

4. Sarzi-Puttini, P., Atzeni, F., Lanata, L., Bagnasco, M. (2013). Efficacy of ketoprofen vs. ibuprofen and diclofenac: a systematic review of the literature and meta-analysis. Clinical and Experimental Rheumatology, 31 (5), 731-738.

5. Davishnia, N. V. (2016). Eksperymentalne obgruntuvannia kombinovanoho zastosuvannia hliukozaminu z ketoprofenom u formi krem-heliu pry osteoartryti. Kharkiv, 20

6. Lyapunov, N. A., Zinchenko, I. A., Bezuglaya, E. P., Lysokobilka, A. A. (2019). Effect of the Ketoprofen Distribution in Cream-gels on the Formation of the Impurities. Drug Development \& Registration, 8 (2), 55-64. doi: http://doi.org/10.33380/23052066-2019-8-2-55-64

7. Buckingham, R. (Ed.) (2020). Martindale: The Complete Drug Reference. London: Pharmaceutical Press, 4912.

8. Patil, S. J., Shirote, P. J. (2012). Synthesis and evaluation of carrier linked prodrug of ketoprofen with glucosamine. Journal of Pharmacy Research, 5, 954-957. Available at: http://jprsolutions.info/files/final-file-57de8ca6e160e8.65433122.pdf

9. The European Pharmacopoeia (2019). European Directorate for the Quality of Medicines \& HealthCare of the Council of Europe. Strasbourg, 5224.

10. British Pharmacopoeia (2020). London: The Stationery Office. Available at: https://www.pharmacopoeia.com/

11. The United States Pharmacopoeia, 41 - NF 36 (2018). The United States Pharmacopoeial Convention. Rockville. Available at: https://www.worldcat.org/title/united-states-pharmacopeia-2018-usp-41-the-national-formulary-nf-36/oclc/1013752699

12. Derzhavna Farmakopeia Ukrainy. Vol. 1 (2015). Kharkiv: Derzhavne pidpryiemstvo «Ukrainskyi naukovyi farmakopeinyi tsentr yakosti likarskykh zasobiv», 1128.

13. Dhokchawle, B., Tauro, S., Bhandari, A. (2015). Ester Prodrugs of Ketoprofen: Synthesis, Hydrolysis Kinetics and Pharmacological Evaluation. Drug Research, 66 (1), 46-50. doi: http://doi.org/10.1055/s-0035-1548908

14. Redasani, V. K., Bari, S. B. (2012). Synthesis and evaluation of mutual prodrugs of ibuprofen with menthol, thymol and eugenol. European Journal of Medicinal Chemistry, 56, 134-138. doi: http://doi.org/10.1016/j.ejmech.2012.08.030

15. Chawla, G., Ranjan, C., Kumar, J., A. Siddiqui, A. (2017). Chemical Modifications of Ketoprofen (NSAID) in Search of Better Lead Compounds: A Review of Literature From 2004-2016. Anti-Inflammatory \& Anti-Allergy Agents in Medicinal Chemistry, 15 (3), 154-177. doi: http://doi.org/10.2174/1871523016666170217094722

16. Choi, H.-K., Chun, M.-K., Lee, S. H., Jang, M. H., Kim, H. D., Jung, C. S., Oh, S. Y. (2007). In vitro and in vivo study of poly(ethylene glycol) conjugated ketoprofen to extend the duration of action. International Journal of Pharmaceutics, 341 (1-2), 5057. doi: http://doi.org/10.1016/j.ijpharm.2007.03.045

17. Note for Guidance on Impurities in New Drug Products (2006). CPMP/ICH/2738/99 (ICH Topic Q3B (R2)). Available at: https://www.ema.europa.eu/en/documents/scientific-guideline/ich-q-3-b-r2-impurities-new-drug-products-step-5_en.pdf b19907

18. Muro, S. (Ed.) (2016). Drug Delivery Across Physiological Barriers. Pan Stanford Reference, 426. doi: http://doi.org/10.1201/

19. Alkilani, A., McCrudden, M. T., Donnelly, R. (2015). Transdermal Drug Delivery: Innovative Pharmaceutical Developments Based on Disruption of the Barrier Properties of the Stratum Corneum. Pharmaceutics, 7 (4), 438-470. doi: http://doi.org/10.3390/ pharmaceutics7040438

20. Bezuglaya, E. P., Zinchenko, I. A., Lyapunov, N. A., Stolper, Yu. M. (2019). Pat. No. 2685436 C1 RU. Transdermalniy preparat dlya lecheniya i profilaktiki bolezney sustavov i myagkikh tkaney. MPK: A61K 31/7008, A61K 31/192, A61K 31/351, A61K 47/10, A61P 19/02. declareted: 22.06.2018; published: 18.04.2019, No. 11.

21. Zinchenko, I. A., Lyapunov, N. A., Bezuglaya, E. P. (2017). Study of the formation of ketoprofen impurities in model solutions. Farmakom, 4, 16-22. 
22. Sheskey, P. J., Hancock, B. C., Moss, G. P., Goldfarb, D. J. (Ed.) (2020). Handbook of Pharmaceutical Excipients, Ninth edition. London: Pharm. Press, 1296.

23. Lyapunov, A. N. (2015). Solubility study of meloxicam and meloxicam trometamol in some non-aqueous solvents and mixed solvents. Farmakom, 2, 41-48.

24. Note for Guidance on Pharmaceutical Development, Part I (2009). EMEA/CHMP/167068/2004 (ICH Topic Q 8 (R2) Pharmaceutical Development).

25. LGC standards. Available at: https://www.lgcstandards.com

26. TLC standards. Available at: https://www.tlcstandards.com

27. Onigbinde, A., Nicol, G., Munson, B. (2001). Gas Chromatography/Mass Spectrometry of Polyethylene Glycol Oligomers. European Journal of Mass Spectrometry, 7 (3), 279-291. doi: http://doi.org/10.1255/ejms.438

28. Lyapunov, N. A., Zinchenko, I. A., Bezuglaya, E. P. (2018). Identification and assay of the ketoprofen esters. Belgorod State University Scientific Bulletin Medicine Pharmacy, 41 (3), 473-483. doi: http://doi.org/10.18413/2075-4728-2018-41-3-473-483

29. Note for Guidance on Validation of Analytical Procedures: Text and Methodology, Step 5 (1995). CPMP/ICH/381/95 (ICH Topic Q 2 (R1) Validation of Analytical Procedures: Text and Methodology).

Received date 11.05.2021

Accepted date 08.06.2021

Published date 30.06.2021

Elena Bezuglaya, PhD, Senior Researcher, Head of Laboratory, Laboratory of Technology and Analysis of Medicinal Products, State Scientific Institution "Institute for Single Crystals" of National Academy of Sciences of Ukraine, Nauky ave. 60, Kharkiv, Ukraine, 61072

Zinchenko Igor, PhD, Junior Researcher, Laboratory of Technology and Analysis of Medicinal Products, State Scientific Institution "Institute for Single Crystals" of National Academy of Sciences of Ukraine, Nauky ave. 60, Kharkiv, Ukraine, 61072

Lyapunov Nikolay, Doctor of Pharmaceutical Sciences, Professor, Leading Researcher, Laboratory of Technology and Analysis of Medicinal Products, State Scientific Institution "Institute for Single Crystals" of National Academy of Sciences of Ukraine, Nauky ave. 60, Kharkiv, Ukraine, 61072

Hanna Vlasenko, PhD, Junior Researcher, Department of Luminescent Materials and Dyes, State Scientific Institution "Institute for Single Crystals" of National Academy of Sciences of Ukraine, Nauky ave. 60, Kharkiv, Ukraine, 61072

Vladimir Musatov, PhD, Senior Researcher, Department of Organic and Bioorganic Chemistry, State Scientific Institution "Institute for Single Crystals" of National Academy of Sciences of Ukraine, Nauky ave. 60, Kharkiv, Ukraine, 61072

*Corresponding author: Elena Bezuglaya, e-mail: bezugla.op@gmail.com 